\title{
Estudos sobre a biologia e hábitos alimentares de Culex quinquefasciatus Say de Manaus, Amazonas, Brasil
}

\author{
J. Derek Charlwood (")
}

\section{Resumo}

Estudo sobre Culex quinquefasciatus Say, um vetor potencial da filariose urbana em Manaus, Amazonas. Foram realizadas coletas de populaçōes no ato de picar e em repouso. Os estágios de desenvolvimento ovariano e paridade foram determinados pelo exame do aspecto externo do abdome e a dissecção para dilatações de ovaríolos. A maioria das fêmeas parece repousar após a ovoposição antes de voltar a alimentar-se. O ato de picar ocorria dentro das casas, com picos ao entardecer e por volta da meia-noite. A mortalidade diária era semelhante à das áreas em que ocorre a transmissão de filariose. Coletas com armadilhas, dos individuos em repouso, indicaram que ocorrem pequenas flutuaçōes em números durante o ano, e a análise de 274 refeiçōes de sangue demonstrou que o homem era o hospedeiro preferido.

\section{INTRODUÇÃo}

Um dos resultados do aumento da urbanização mundial desde a Segunda Guerra tem sido o aumento nas populações do mosquito Culex quinquefasciatus Say (= fatigans) (Mattingly 1969), o qual, em muitas áreas, é o vetor da filariose urbana, Wuchereria bancrofti. De fato, esta espécie foi um vetor em Manaus no passado (Rachou et al., 1955; Rachou \& Lacerda, 1956), e onde quer que exista uma grande população de $C$. quinquefasciatus, existe também o risco de uma proliferação da doença. Além disso, a doença tem um início insidoso e não produz sintomas dramáticos, nos primeiros anos da infecção, o que torna difícil a determinação epidemiológica.

Desde que muitas áreas da cidade de Manaus possuem grandes populações do mosquito, um estud foi empreendido para determinar a capacidade vetorial do inseto na cidade. Este trabalho refere-se aos resultados obtidos de novembro de 1977 a agosto de 1978, quando o estudo terminou.

\section{LOCAIS DE INVESTIGAÇÃO}

$\mathrm{O}$ distrito urbano de Coroado, $4 \mathrm{~km}$ nordeste do centro da cidade de Manaus, foi escolhido para a investigação. A área é densamente povoada e contém mais de 15.000 pessoas em aproximadamente $4 \mathrm{~km}^{2}$ de terra. A maioria das casas da área é de madeira e tem privadas do lado de fora. Na época do estudo não existia luz elétrica nem água encanada disponíveis. A maioria das pessoas dorme em redes e não utilizava mosquiteiros. Todos esses fatores propiciam condições favoráveis à procriação do mosquito.

Um armazém no limite do distrito foi escolhido como a estação de amostragem (cf. fig. 1). A vantagem desta escolha é que as coletas realizadas durante a picada, dentro de casa, não atrapalhavam os ocupantes durante o dia ou durante a noite.

De novembro de 1977 a agosto de 1978, foram tomadas amostras nesse armazém numa base quase diária. $O$ trabalho foi interrompido em agosto de 1978, quando o armazém foi convertido em um depósito de móveis e a família que ali residia, de 5 pessoas, mudou-se.

\section{MÉTodos}

POPULAÇÃO EM REPOUSO

Cilindros de papelão de $160 \mathrm{~mm}$ de altura e $170 \mathrm{~mm}$ de diâmetro, revestidos com papel preto, foram usados como armadilhas para as amostras da população em repouso. Os cilíndros foram colocados de 0 a 3,5 metros acima do chão de um quarto de dormir ocupado por dois adultos e uma criancinha. Os mosquitos pousados dentro dos cilíndros foram capturados cada manhã, cobrindo-se rapida-

(*) Instituto Nacional de Pesquisas da Amazônia, Manaus. 


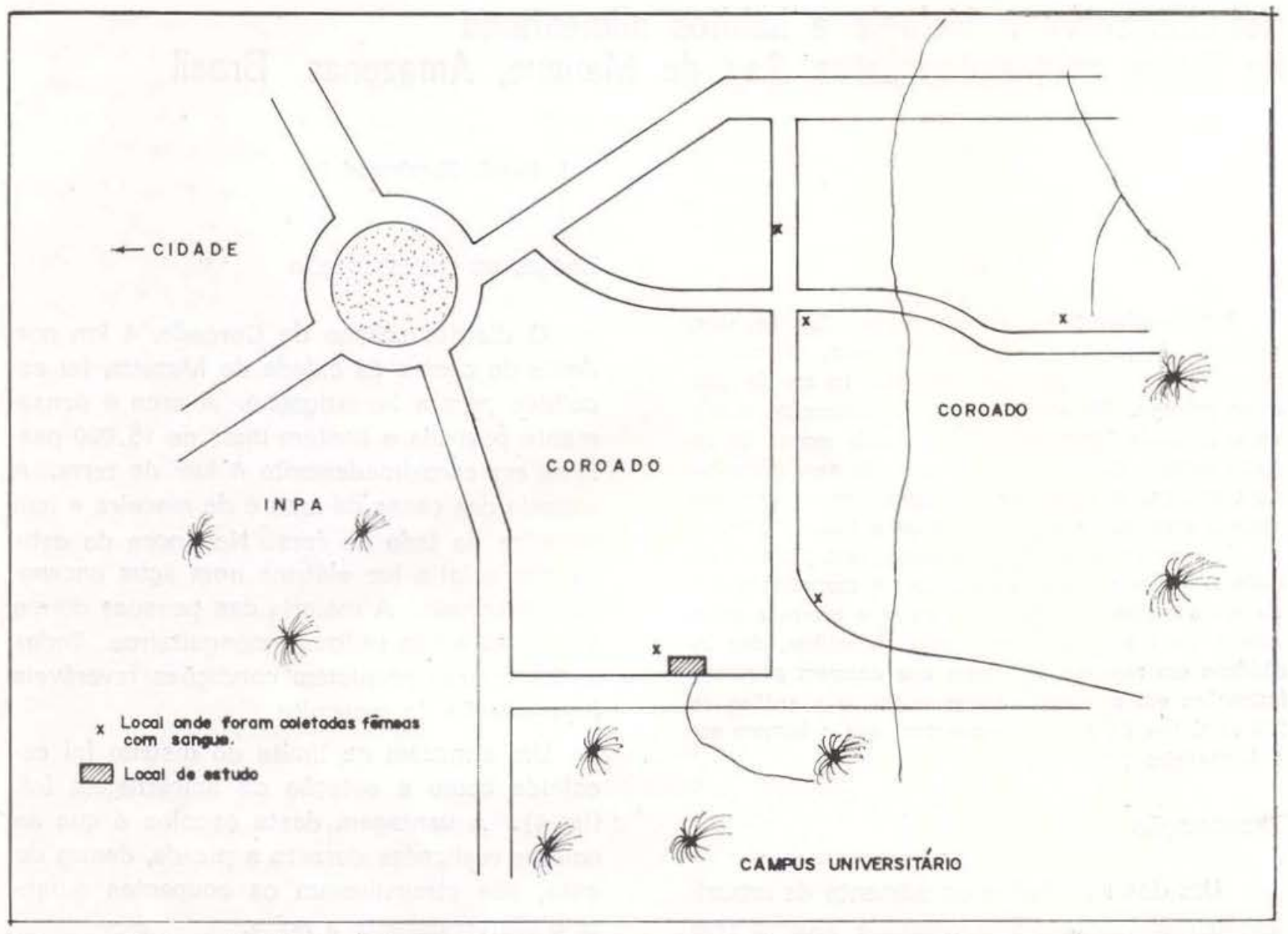

Fig. 1 - Mapa do Coroado com a estação de coleta marcada e localizaçōes de fontes de fêmeas alimentadas com sangue.

mente o topo de cada cilindro com uma tam. pa. Os cilindros com os mosquitos eram então levados ao laboratório para classificação. Seis cilindros idênticos substituíam os levados ao laboratório. Os insetos eram mortos com clorofórmio e separados pelo sexo. $\mathrm{Na}$ última parte do estudo (maio a julho) as fêmeas eram classificadas, de acordo com a aparência externa do abdome, nas categorias : alimentadas com sangue, não alimentadas, semigrávidas e grávidas.

Quatro a seis amostras foram obtidas por semana durante a maior parte do estudo.

\section{COLETA DE INDIVÍDUOS NO ATO DE PICAR}

Uma série de coletas de indivíduos no ato de picar durante toda a noite $(18: 00-06: 00$ horas), foi realizada perto do quarto de dormir da família residente, de maio a agosto de 1978. Uma equipe de três coletores trabaIhou em três turnos de quatro horas e as coletas foram realizadas em, pelo menos, três noites consecutivas, cada mês. Os coletores revezavam-se nos turnos cada noite e, quando não estavam coletando, os dois assistentes de folga dormiam sob mosquiteiros, próximo ao local de coleta.

Os insetos eram coletados conforme vinham alimentar-se na parte inferior exposta da perna do coletor. Usando-se lanternas, um tubo de ensaio numerado era colocado sobre a fêmea assim que ela começava a picar. Um tampão de algodão era colocado no tubo para evitar que o inseto escapasse e desse modo os insetos podiam ser coletados individualmente em cada tubo. O momento em que cada inseto era capturado foi anotado. Os 
primeiros mosquitos capturados, cada noite, eram levados ao laboratório, identificados e dissecados pelo autor, usando a técnica de Polovodovada (1949) para determinar suas idades fisiológicas (Detinova, 1962, Gillies \& Wilkes, 1965). Dois terços dos mosquitos restantes da coleta eram dissecados, na manhã seguinte. Durante a dissecação, eram determinados o estágio do desenvolvimento ovariano (Christophers, 1911) e a condição do pedúnculo folicular.

\section{IDENTIFICAÇÃO DA REFEIÇÃO DE SANGUE}

C. quinquefasciatus alimentados de sangue e em repouso foram coletados, com aspiradores, em quatro locais no Coroado (cf. fig. 1). Eram esmagados num papel de filtro e enviados ao Dr. P. L. F. Boreham na Inglaterra, para determinação da fonte do sangue (Boreham, 1975).

\section{RESUltados}

COLETAS DE INDIVÍDUOS EM REPOUSO

A média diária total para cada semana de coleta do número de fêmeas apanhadas nos cilindros é mostrada na Figura 2. As flutuações relativamente pequenas nos números, de semana a semana, podem ser resultado do clima sempre agradável que existe em Manaus.
A Figura 3 mostra a fraca média numérica de machos e fêmeas em repouso nos cilindros, expressa como média numérica por amostra por semana. Tanto os machos quanto as fêmeas preferiram repousar a $2,5 \mathrm{~m}$ acima do nivel do solo. Durante a amostragem de uma semana, o quarto foi deixado desocupado durante o dia, a fim de testar-se se esse nivel preferido era um reflexo da perturbação que os insetos sofriam durante o dia nos niveis mais baixos. A média das amostras de 5 dias é dada no gráfico pontilhado na Figura 3. Pode observar-se que não existe diferença marcante entre a coleta dessas semanas e as amostras das outras semanas.

A percentagem das fêmeas capturadas e classificadas de acordo com seu aspecto abdominal é dada na Tabela 1. Não existe diferença significativa usando-se o teste de $X^{2}$, entre a coleta por meio de cilindro e as coletas convencionais de indivíduos em repouso realizadas nos quatro outros locais do Coroado. A população em repouso da casa era heterogênea, sendo a menor proporção em cada caso, da população grávida. Os locais de ovoposição, sobretudo as latrinas externas, estão situados a poucos metros das casas e são utilizados como locais de repouso para fêmeas recém-emergidas e grávidas e devem ser levados em conta na relativa escassez dessas duas categorias nas coletas. As fêmeas re-

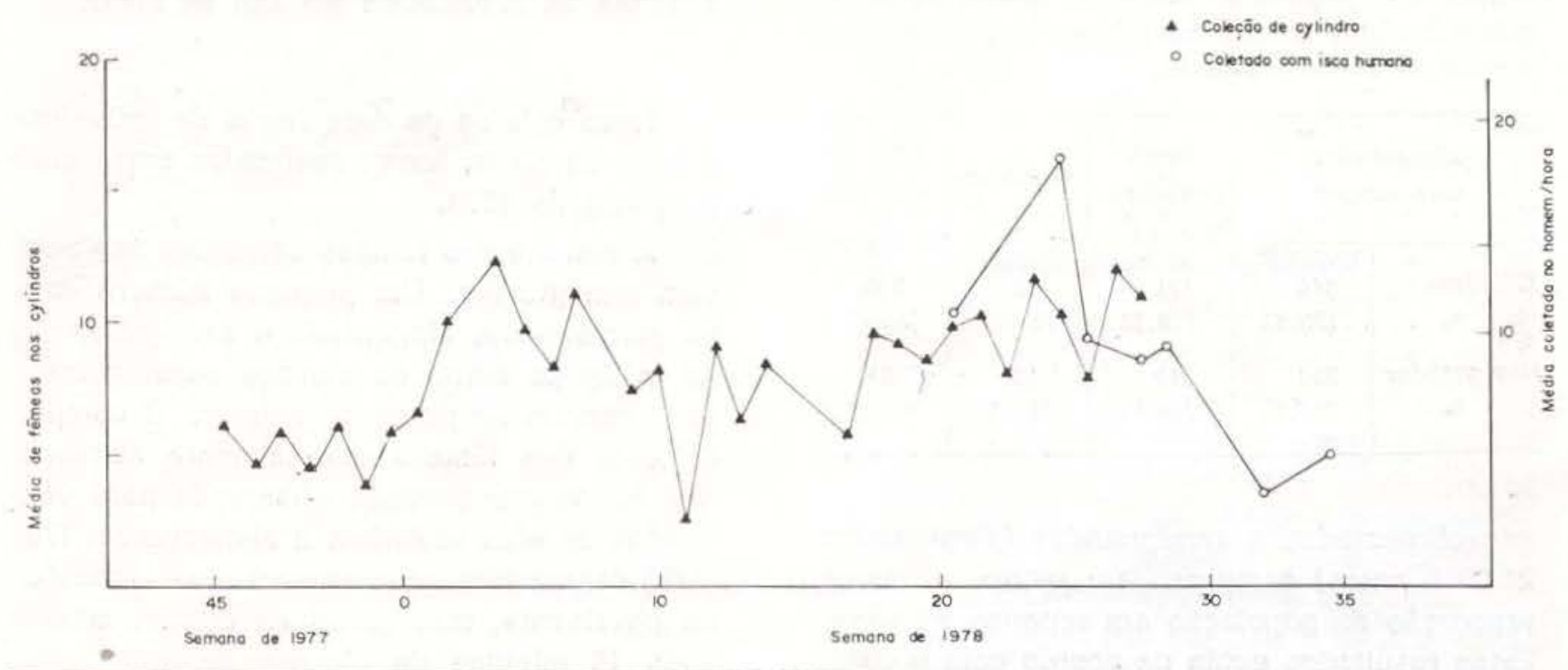

Fig. 2 - Médias semanais dos números totais de fêmeas apanhadas nos cilindros com as médias numéricas dos indivíduos coletados no ato de picar por coleta de 3 noites. 

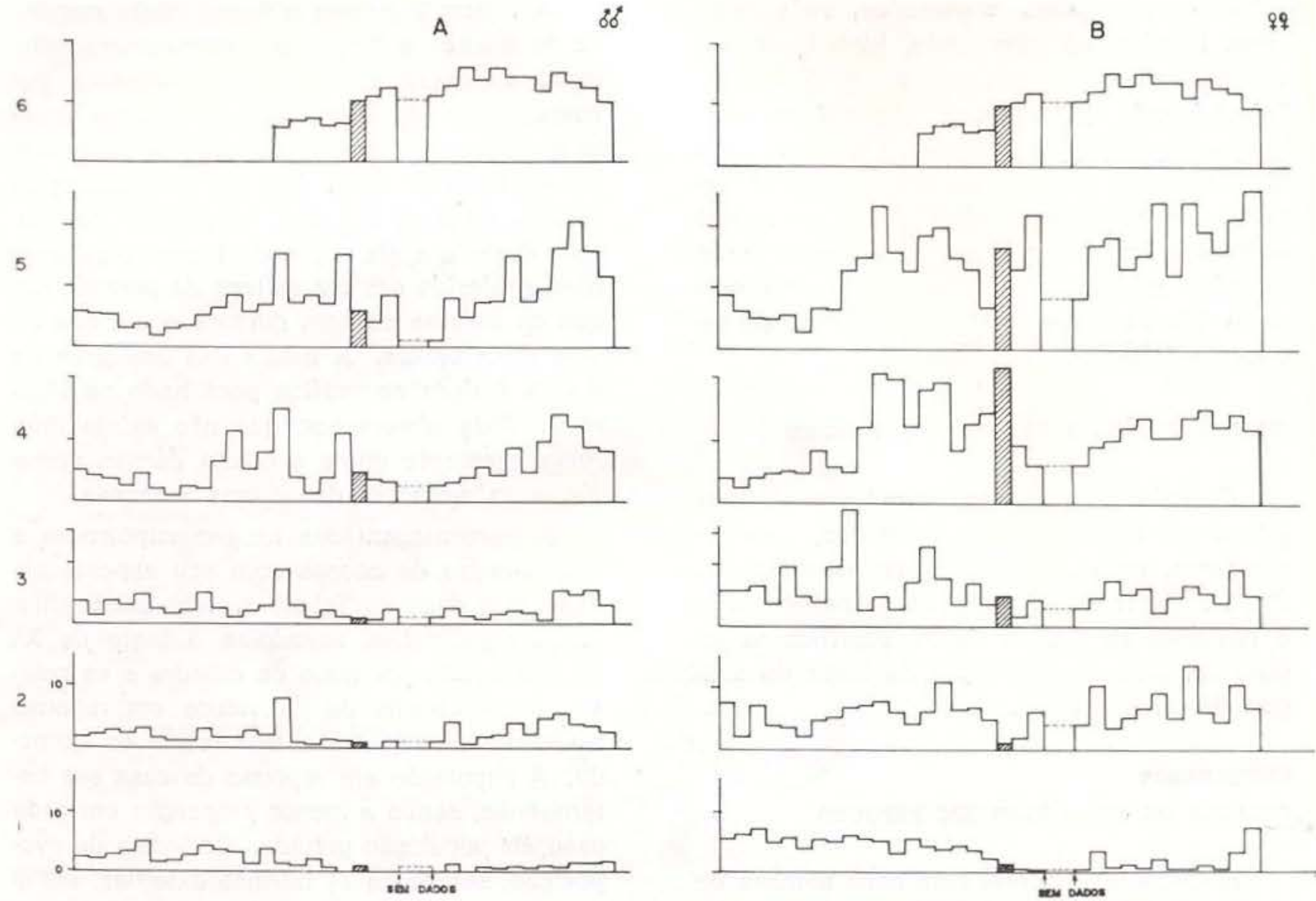

Fig. 3-Média numérica semanal de machos e fêmeas apanhados quando repousavam nos cilindros. $1=0,0 \mathrm{~m}$, $2=0,5 \mathrm{~m}, 3=1,0 \mathrm{~m}, 4=2,0 \mathrm{~m}, 5=3,0 \mathrm{~m}, 6=3,5 \mathrm{~m}$ acima do nivel do chāo.

TABELA 1 - Aspecto abdominal de fêmeas de Culex quinquefasciatus obtidas em coletas de indivíduos em repouso no Coroado, Manaus.

\begin{tabular}{c|c|c|c|c}
\hline \multicolumn{2}{c|}{$\begin{array}{c}\text { Alimentadas } \\
\text { com sangue }\end{array}$} & $\begin{array}{c}\text { Semi- } \\
\text { grávidas }\end{array}$ & Grávidas & $\begin{array}{c}\text { Não ali- } \\
\text { mentadas }\end{array}$ \\
\hline $\begin{array}{c}\text { Cilindros } \\
\%\end{array}$ & $\begin{array}{l}344 \\
(39.5)\end{array}$ & $\begin{array}{c}171 \\
(19.5)\end{array}$ & $\begin{array}{c}43 \\
(5.0)\end{array}$ & $\begin{array}{c}316 \\
(36.0)\end{array}$ \\
$\begin{array}{c}\text { Nas paredes } \\
\%\end{array}$ & $\begin{array}{l}230 \\
(55.0)\end{array}$ & $\begin{array}{c}19 \\
(19.0)\end{array}$ & $\begin{array}{c}18 \\
(4.0)\end{array}$ & $\begin{array}{c}91 \\
(22.0)\end{array}$ \\
\hline
\end{tabular}

cém-alimentadas e semigrávidas (alimentadas 24-60 h antes) compreendem juntas a maior proporção da população em repouso na casa. Estes resultados estão de acordo com o comportamento endofílico normalmente associado com C. quinquefasciatus.
COLETAS DE INDIVÍDUOS NO ATO DE PICAR

Treze coletas de doze horas de indivíduos no ato de picar, foram realizadas entre maio e agosto de 1978.

A maioria das fêmeas coletadas não estavam alimentadas. Um pequeno número estava parcialmente alimentado e semigrávido e, no início da noite, os machos ocasionalmente pousavam na perna do coletor. O comportamento das fêmeas parcialmente alimentadas foi cuidadosamente observado para verificar-se se elas voltariam a alimentar-se. Três $(5 \%)$ dessas fêmeas pousaram para alimentarse novamente, mas todas as outras, mesmo após 15 minutos de observação, não tentaram alimentar-se. A dissecação dessas fêmeas revelou que todas elas possuiam ová. 
rios com folículos em diferentes estágios de desenvolvimento (do início do estágio II ao final do estágio IV, com degeneração muito aparente.

Por outro lado, as fêmeas não alimenta das começavam a alimentar-se imediatamente após pousadas no coletor e apenas os dados relativos a essas fêmeas são apresentados abaixo.

Os ciclos de picadas das coletas, representados no total de picadas, cada 15 minu. tos, de maio a julho, são dados na Figura 4, e a média dos números capturados pelo homem/hora cada mês é dado na Figura 2. Isto fornece a coleta total por coleta de 3 noites de cada mês e a pirâmide de idades obtida pela dissecação das fêmeas de tais coletas.

Os mosquitos começavam a picar logo após o por do sol (18:00 horas) e continua-
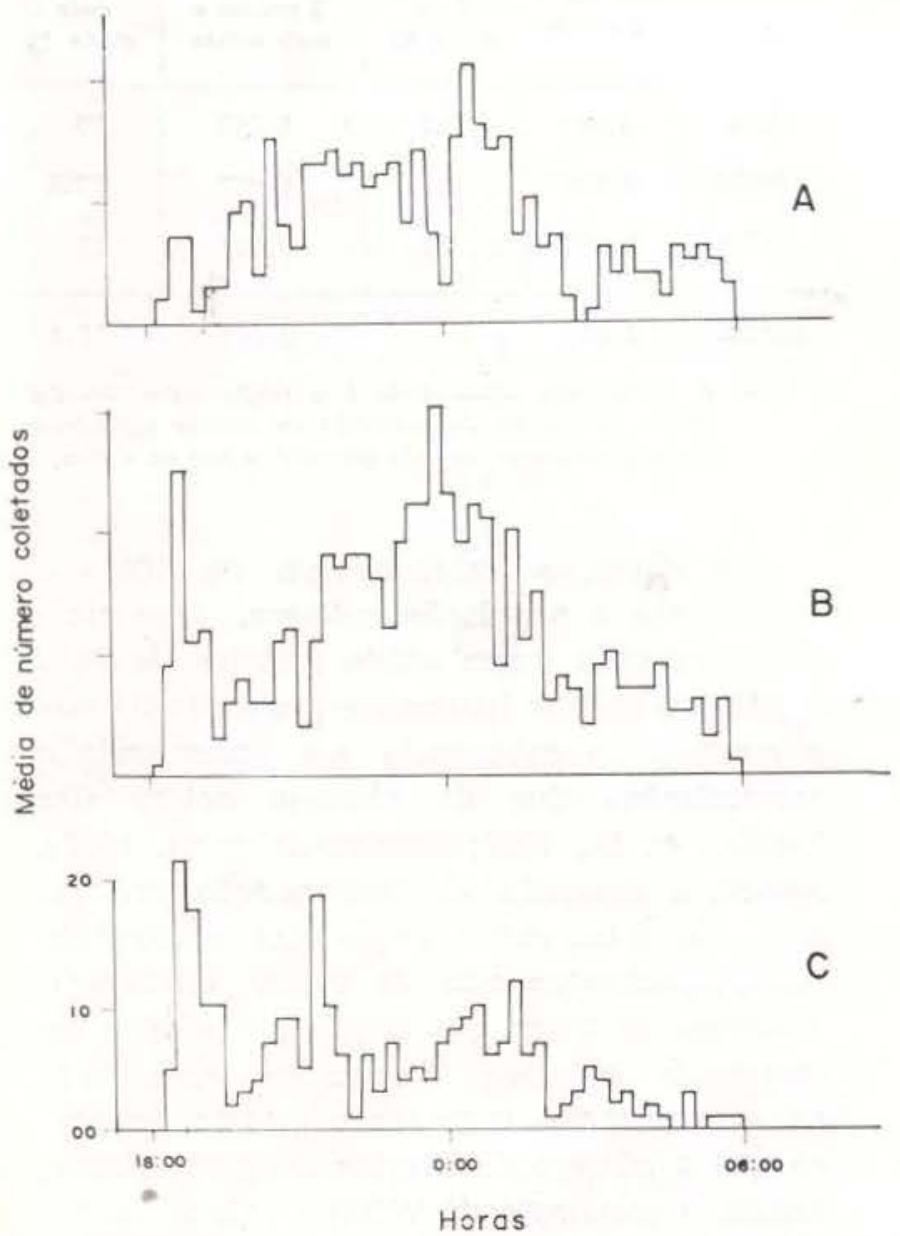
vam até o amanhecer (06:00 horas). Ocorria

um pico de atividade de picada por volta da meia-noite e nas coletas de junho e julho ocorreu um breve pico de atividade de picada ao entardecer.

Para as dissecaçōes de cada mês a estrutura de idade da população era semelhante. A fêmea mais velha dissecada tinha quatro vestígios de dilatações ovariolares, tendo sido, conseqüentemente, coletado quando vinha para sua quinta alimentação. Em contraste com os resultados de Samarawickrema (1967) no Ceilão, apenas uns poucos mosquitos dissecados possuiam sacos do ovariolos distendidos (Detinova 1962, Gillies \& Wilkes 1965). A tabela II mostra que a maioria dos mosquitos fêmeas paridas dissecadas possuíam relíquias bem definidaș (fig. 5). O saco deixado na ovoposição prévia permanece elástico por aproximadamente 10 horas após a ovoposição e não apresenta sinais de contração. Contração
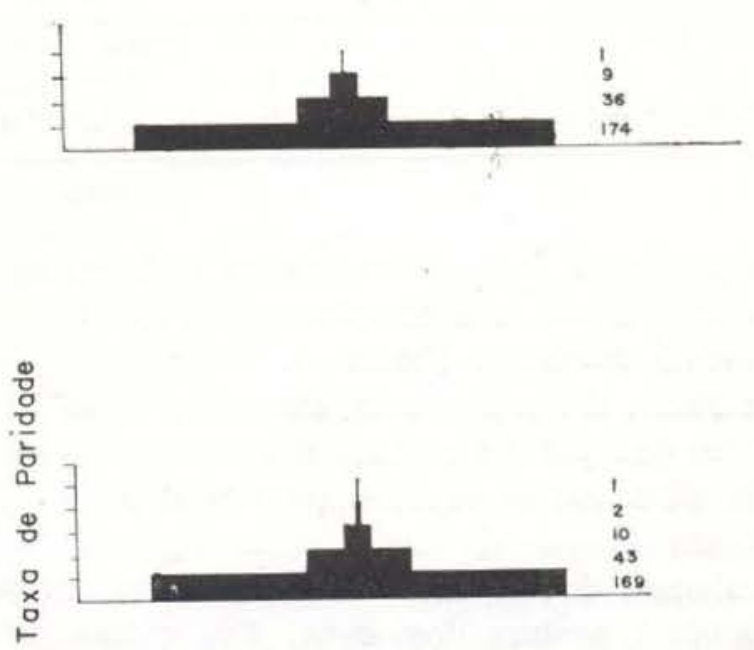

Fig. 4 - Ciclos de picadas e pirâmides de idade de C. quinquefasciatus, A - maio, B - junho, C - julho. 
TABELA 2 - Estágios do saco de mosquitos paridos dissecados.

\begin{tabular}{cc|c|c|c|c|c}
\hline \multicolumn{7}{c}{ Estágio do saco } \\
\hline \multicolumn{2}{c|}{ a } & b & $c$ & d & Sem saco & Total \\
\hline N.o & 17 & 13 & II & 22 & 88 & 151 \\
$\%$ & (II.3) & $(8.6)$ & $(7.3)$ & $(14.6)$ & $(58.3)$ & \\
\hline
\end{tabular}

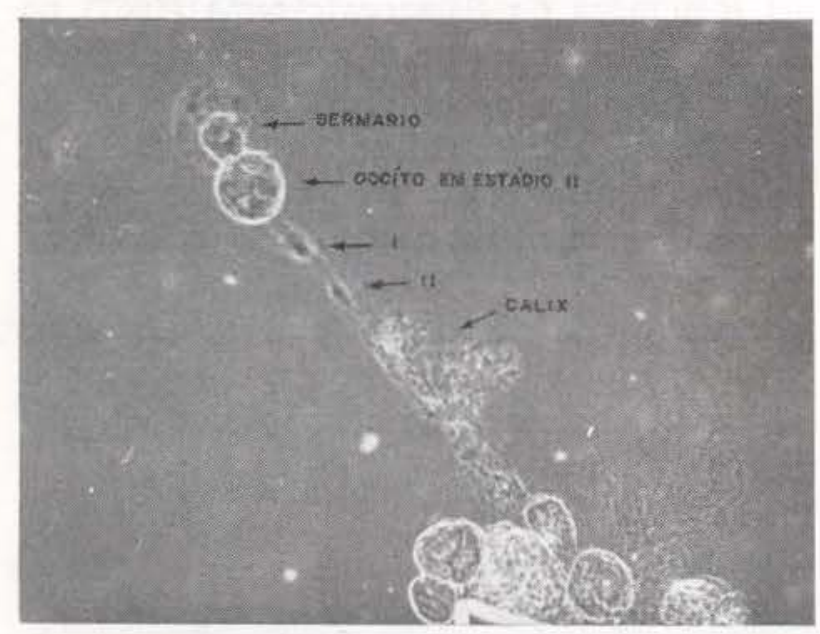

Fig. 5 - Dissecaçăo de uma fêmea bipara (que foi coletada quando vinha para sua terceira alimentaçāo); demonstrando os vestígios ovariolares bem definidos.

definida do saco ocorre apenas 12 horas após a ovoposição e é completa após aproximadamente 24 horas (Detinova, 1962; Samarawickrema, 1967). Portanto, elas tinham vestígios bem definidos: a maioria das fêmeas que viera alimentar-se repousa para pelo menos 24 horas depois da ovoposição. Apenas 11\% voltaram diretamente a alimentar-se em seguida à postura dos ovos. Em outras palavras, a $C$. quinquefascistus em Manaus, pode ser um dia ou mais, mais longe do que o ciclo da mesma espécie no Ceilão (Samara. wickrema, 1967). No laboratório, a ovoposição ocorre de 3 a 5 dias, após uma refeição de sangue. Assim, supondo-se um ciclo gonotrófico de 4 dias, é possível estimar a mortalidade diária, usando-se o método de taxa de parição. $O$ princípio do cálculo é esclarecido no seguinte exemplo: a taxa unípara em maio era 0,264 . Portanto, a probabilidade de um mosquito sobreviver durante um dia $(p)$, com um ciclo gonotrófico de 4 dias, é de 0,716 $\left(\mathrm{p}^{4}=0,264\right)$, dando uma sobrevivência diária de $72 \%$ e conseqüentemente uma mortalidade diária de $28 \%$. Semelhantemente, a proporção de sobrevivência para duas ovoposições é de $0,057 \%$ para o mesmo mês. A probabilidade de sobrevivência de um mosquito durante o dia $(p)$ é então $0,70\left(p^{8}=0,057\right)$ a qual fornece uma mortalidade diária de $30 \%$. A tabela III dá a mortalidade diária para maio a julho, para as populações ovíparas e multíparas e a fig. 6 mostra as curvas de sobrevivência para a população no ato de picar nesses instantes.

TABELA 3 - Proporção de paridas e mortalidade diária calculada de $C$. quinquefasciatus de Manaus (").

\begin{tabular}{c|c|c|c|c}
\hline MEs & \multicolumn{2}{|c|}{ UM cICLo } & \multicolumn{2}{c}{ DoIs cICLos } \\
\hline & $\begin{array}{c}\text { Proporçáo } \\
1 \text { parida }\end{array}$ & $\begin{array}{c}\text { Mortali- } \\
\text { dade } \\
\text { diária } \%\end{array}$ & $\begin{array}{c}\text { Proporçáo } \\
\text { 2 paridas e } \\
\text { mais velhos }\end{array}$ & $\begin{array}{c}\text { Mortoli- } \\
\text { dade } \\
\text { diária \% }\end{array}$ \\
\cline { 2 - 5 } Maio & 0.264 & 28 & 0.057 & 30 \\
Junho & 0.331 & 24 & 0.077 & 27.5 \\
Julho & 0.408 & 20 & 0.067 & 29 \\
\hline Média & 0.33 & 24 & 0.067 & 28.8
\end{tabular}

(*) - A mortalidade diária dada é a média aritmética dos valores calculados da proporçấo de paridas supondo-se que o comprimento do ciclo gonotrófico seja de 4 dias.

$\mathrm{Na}$ figura, a sobrevivência de $100 \%$ é equivalente à população nulípara. A mortalidade em cada grupo etário (médias de $24 \%$ e $29 \%$ ) é apenas levemente mais alta do que a mortalidade encontrada em áreas onde a transmissão ativa da filariose ocorre (De Meillon et al., 1967; Samarawickrema, 1967). Assim, a ausência da transmissão em Manaus não é um resultado de uma mortalidade excepcionalmente alta do vetor. Também é interessante notar que o número efetivo de mosquitos ovíparos dissecados cada mês permanece mais ou menos o mesmo, ao passo que o número de insetos nulíparos flutua. Assim, a proporção de vetores potenciais pode mudar durante o ano, mas o número efetivo pode permanecer o mesmo. 


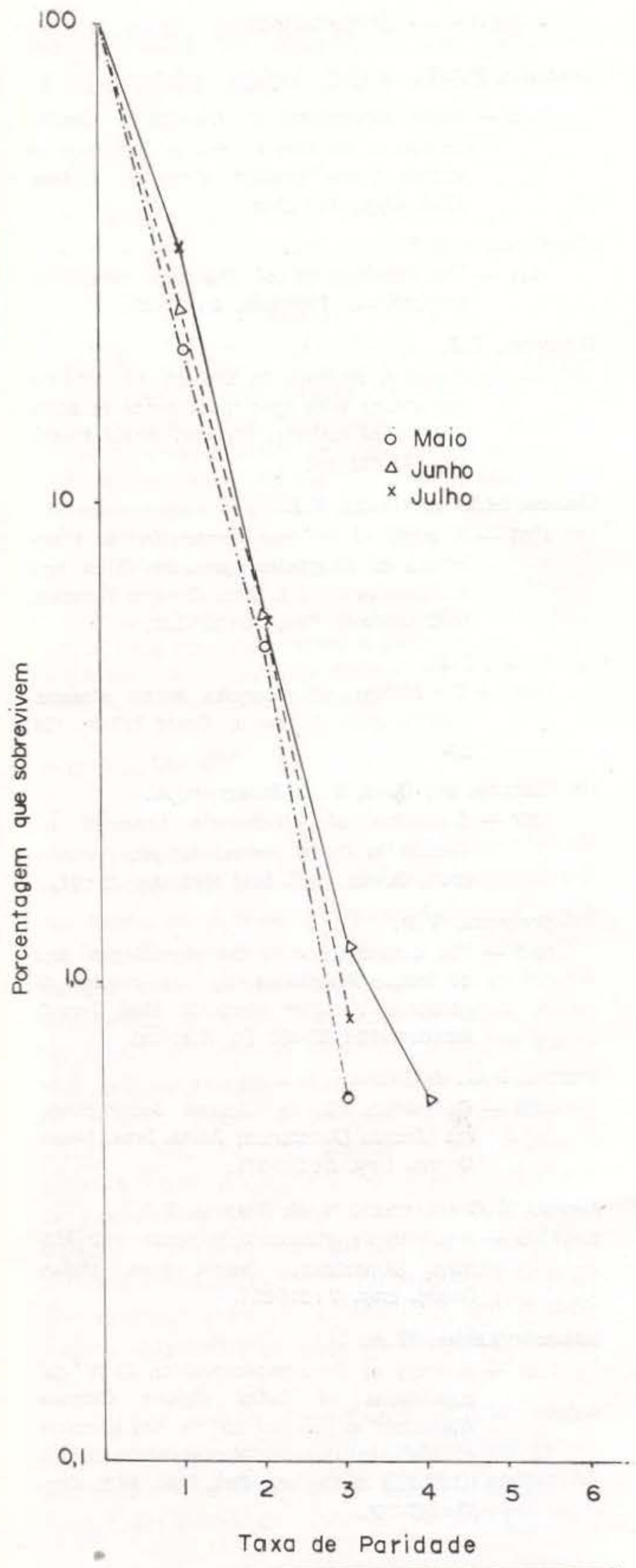

Fig. 6-Curvas de sobrevivência obtidas a partir das fêmeas dissecadas.

\section{ANÁLISE DA REFEIÇÃO DE SANGUE}

A tabela IV mostra que de 274 fêmeas examinadas, a maioria havia-se alimentado no homem, o que não é surpreendente considerando-se os hospedeiros disponíveis na área. De todas as refeiçöes de sangue, apenas uma foi identificada como sendo de cachorro, o segundo mais comum hospedeiro potencial na área. Um por cento das refeições apresentou fontes mistas de sangue (Homem e Galiformes), pois 3 fêmeas haviam feito refeição em ambos os hospedeiros. Não se sabe se qualquer das fêmeas comprovadamente alimentadas no homem, haviam-se alimentado em dois humanos.

TABELA 4 - Análise de refeições de sangue de 274 mosquitos em repouso, obtidos em abrigos fora das casas no Coroado, Manaus.

\begin{tabular}{l|c|c}
\hline Hospedeiro & $\begin{array}{c}\text { Número de } \\
\text { refeiçōes }\end{array}$ & $\begin{array}{c}\text { Percentagem } \\
\text { do total }\end{array}$ \\
\cline { 2 - 3 } Homem & 214 & 79 \\
Galiformes & 44 & 16 \\
Columbiformes & 3 & 1 \\
Cão & 1 & 0.3 \\
Mistos & 3 & \\
Homem e Galiformes & 4 & 1 \\
Mamífero & 1 & 1.3 \\
Pássaro & 3 & 0.3 \\
Negativo & & 1 \\
\hline
\end{tabular}

Nas coletas de picada, as fêmeas levaram de 3 a 17 minutos para encher-se nas pernas expostas dos coletores (média de 9 minutos na variação de 3-17 minutos, para 15 fêmeas). Este longo tempo de alimentação, em conjunto com os quartos de dormir muito povoados da maioria das casas, torna possiveis a alimentação intermitente e a alimentação de sangue em mais de uma pessoa.

\section{DISCUSSÃo}

Os resultados deste estudo são de muitos modos similares aos obtidos por Samarawickrema (1967) em seu estudo mais extenso, no Ceilão. 
Dois aspectos de comportamento das populaçōes de Manaus são importantes em relação ao potencial de transmissão da doença : a) que existe um pico no número de picadas no início da noite e b) que a maioria das fêmeas parece ter um período de repouso, após a ovoposição e antes de sua próxima refeição de sangue. Assim, mesmo que os mosquiteiros fossem usados pela população local, se a transmissão está correndo, esta seria picada pelos mosquitos infectados antes de recolher-se para dormir. A extensão do ciclo gonotrófico do mosquito, de 4 ou mesmo 5 dias, o que significa que as fêmeas não necessitam ser fisiologicamente muito velhas antes que possam tornar-se vetores da doen. ça.

A população de $C$. quinquefasciatus de Manaus mostrou-se fisiologicamente capaz de transmitir a filariose (Rachou \& Lacerda, 1956). Se considerar-se a grande população, a alta taxa de sobrevivência e a preferência apresentada por $C$. quinquefasciatus pelo sangue humano, entăo o potencial desta espécie como um vetor da filariose em Manaus deve ser alto.

\section{AgRADECIMENTOS}

Gostaria de agradecer ao Dr. P. L F. Boreham pela realização das análises das refe:ções de sangue e também gostaria de agradecer a T. J. Wilkes, Dr. L. A. Lacey e Altimiro Soares por sua ajuda durante o decorrer deste estudo.

\section{SUMMARY}

A study was made of Culex quinquefasciatus Say

a potential vector of urban filariasis in Manaus Amazonas. Catches were made of the biting and resting populations. The stages of ovarian development and parity were determined by examination of the external appearence of the abdomen and dissection for ovariole dilations. Most females appeared to rest after oviposition before returning to feed. Biting took place inside houses with peaks at dusk and around midnight. Daily mortality was similar to that in areas where transmission of filariasis occurs. Resting trap catches indicated that there was little fluctuation in numbers throughought the year and analysis of 274 blood meals demonstrated that man was the preferred host.

\section{BIBLIOGRAFIA}

BOREHAM, P.L.F.

1975 - Some applications of bloodmea! identifications in relation to the epidemiology of vector borne tropical diseases. J. trop. Med. Hyg., $78: 83-91$.

Christophers, S.R,

1911 - The development of the egg follicle in anophelines. Paludism, 2: 73-88.

DETINOVA, T.S.

1962 - Age-grouping methods in Diptera of medical importance with special reference to some vectors of malaria. Monogr. World Health Org, $47216 \mathrm{pp}$.

Gillies, M.T. \& WILkES, T.J.

1965 - A study of the age composition of populations of Anopheles gambiae Giles and A. funestus Giles in North-Eastern Tanzania. Bull. entomol. Res. $56: 237-262$.

Mattingly, P.F.

1969 - The biology of mosquito borne disease. George Allen \& Unwin. Great Britain, 184 pp.

De Meillon, B.; Grab, B. \& Sebastian, A.

1967 - Evaluation of Wuchereria bancrofti infection in Culex pipiens fatigans in Rangoon, Burma. Bull. WId Hlth Org $36: 91$.

Polovodovada, V.P.

1949 - The determination of the physiological age of female Anopheles by the number of gonotrophic cycles complete Med. Parasit Moscow $18: 352-355$ (in Russian).

RACHOU, R.G. \& LACERDA, N.B.

1956 - Da transmissão da filariose bancrfoftiana em Manaus (Amazonas) Revta. bras. Malar. Doenç. trop. $8: 369-371$.

Rachou, R.G.: LAcerda, N. \& Barbosa, J.A.

1955 - Inquérito de filarioses humanas em Manaus (Amazonas). Revta. bras. Malar. Doenç. trop. $7: 315-321$.

SAMARAWICKREMA, W.A.

1967 - A study of the age-composition or natural populations of Culex pipiens fatigans Wiedmann in relation to the transmission ci filariasis due to Wuchereria bancrofti (Cobbold) in Ceylon. Bull. Wid. Hith. Org. $37: 117-137$.

(Aceito para publicação em 19/02/79) 